\title{
Effect of fouling on removal of trace organic compounds by nanofiltration
}

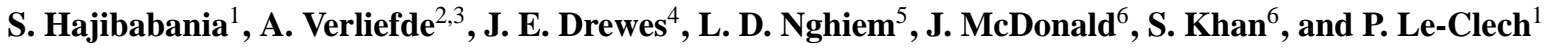 \\ ${ }^{1}$ UNESCO Centre for Membrane Science and Technology, School of Chemical Engineering, \\ The University of New South Wales, Sydney 2052, Australia \\ ${ }^{2}$ Particle and Interfacial Technology Group, Faculty of Bioscience Engineering, Ghent University, \\ Coupure Links 653, 9000 Gent, Belgium \\ ${ }^{3}$ Delft University of Technology, Faculty of Civil Engineering and Geosciences, \\ Department of Sanitary Engineering, P.O. Box 5048, 2600 GA Delft, The Netherlands \\ ${ }^{4}$ Environmental Science and Engineering Division, Colorado School of Mines, Golden, CO 80401-1887, USA \\ ${ }^{5}$ School of Civil Mining and Environmental Engineering, The University of Wollongong, \\ Wollongong, NSW 2522, Australia \\ ${ }^{6}$ Water Research Centre, The University of New South Wales, Sydney 2052, Australia
}

Received: 22 August 2011 - Published in Drink. Water Eng. Sci. Discuss.: 9 September 2011

Revised: 23 November 2011 - Accepted: 23 November 2011 - Published: 21 December 2011

\begin{abstract}
The fate of chemical of concern is not yet fully understood during treatment of impaired waters. The aim of this paper is to assess the impact of different organic-based fouling layers on the removal of a large range of trace organics. Both model and real water samples (mixed with trace organic contaminants at environmental concentration of $2 \mu \mathrm{gl}^{-1}$ ) were used to simulate fouling in nanofiltration under controlled environment. The new and fouled membranes were systematically characterised for surface charge, hydrophobicity and roughness. It was observed that fouling generally reduced the membrane surface charge; however, the alterations of the membrane hydrophobicity and surface roughness were dependent on the foulants composition. The rejection of charged trace organics was observed to be improved due to the increased electrostatic repulsion by fouled membranes and the adsorption of the trace organic chemicals onto organic matters. On the other hand, the removal of nonionic compounds decreased when fouling occurred, due to the presence of cake enhanced concentration polarization. The fouling layer structure was found to play an important role in the rejection of the trace organic compounds.
\end{abstract}

Keywords. Nanofiltration, Fouling, Trace organic compounds, Characterisation

\section{Introduction}

Water recycling, including direct/indirect potable reuse, has been identified as efficient use of available water resources and thereby providing some relief to water scarcity. However, a wide range of trace organic contaminants such as endocrine disrupting compounds (EDCs), pharmaceutically active compounds (PhACs) and pesticides are known to persist (in $\mu \mathrm{gl}^{-1}$ to $\mathrm{ng}^{-1}$ concentrations) in wastewater-treated ef-

Correspondence to: P. Le-Clech (p.le-clech@unsw.edu.au) fluents (Le-Minh et al., 2010; Watkinson et al., 2009). The negative effects of these contaminants on human health as the result of their long term exposure are generally unknown. Therefore, effective removal of trace organic compounds is required to prevent any potential risks of human and environmental exposure (Ongerth and Khan, 2004).

High pressure membrane processes such as nanofiltration (NF) has been increasingly used for treatment of surface water in both direct and indirect potable water recycling applications (Schäfer et al., 2003; Van der Bruggen and Vandecasteele, 2003). The rejection of some trace contaminants trough NF was reported to be incomplete (Van der Bruggen et al., 2008; Van der Bruggen and Vandecasteele, 2003). 
Several studies have been conducted over the last decade to identify the different factors involved in NF rejection mechanisms (Bellona et al., 2004; Bolong et al., 2009; Nghiem and Schäfer, 2006; Radjenovic et al., 2008). It is generally believed that a given solute can be rejected by NF membranes by size exclusion and charge repulsion, and also by adsorption to the membrane surface. All of these mechanisms are largely dependent on both solute (Verliefde et al., 2009) and membrane properties (Boussu et al., 2008). However, detailed understanding of the rejection mechanisms of trace organics by NF, as well as the interactions between trace contaminants and the membrane polymer, fouling layers and other solutes in the solution is still incomplete (Van der Bruggen et al., 2008).

Fouling is an inevitable phenomenon in membrane filtration systems. Besides affecting the permeate flux, fouling alters membrane surface properties. In a previous study, it was reported that membrane surface charge decreased, while contact angle increased, during fouling with surface water (Verliefde et al., 2009). In another example, significant increase of membrane surface roughness was observed as a result of protein fouling (Bowen et al., 2003).

Several studies have investigated the effects of organic and colloidal fouling on membrane performance, with emphasis on permeate flux decline, salt rejection. A number of papers have also focused on the effect of fouling on removal of trace organics (Elimelech and $\mathrm{Ng}$, 2004; Hajibabania et al., 2011; Nghiem and Hawkes, 2009; Verliefde et al., 2009; $\mathrm{Xu}$ et al., 2006; Zazouli et al., 2009). It has been observed that the rejection of trace organic compounds was enhanced when membrane was fouled with humic acid, due to pore restriction (Nghiem et al., 2008). In another study, an increase in rejection of hydrophilic compounds was reported, also due to pore restriction, following NF fouling with varying concentrations of alginate (Xu et al., 2006). Moreover, it was noted that the magnitude of this rejection enhancement was more pronounced for membranes with large pore sizes. A significant increase in rejection of nonionic solutes after fouling with secondary treated wastewater effluent was also reported. This was due to the formation of a fouling layer which isolated the solute-membrane interactions and increased adsorbed mass of hydrophobic nonionic compounds on the fouling layer.

Yangali-Quintanilla et al. reported that the rejection of both charged and neutral compounds decreased due to the occurrence of cake enhanced concentration polarization (CECP) when alginate fouling was established on the membrane surface (Yangali-Quintanilla et al., 2009). It has also been reported that the rejection of compounds by NF membranes fouled with filtered and raw lake waters increased significantly (Comerton et al., 2009). This increased rejection of trace organics was attributed to the higher trace organicorganic complexes in the presence of calcium.

The seemingly contradictory findings in these studies are difficult to untangle since NF rejection mechanisms are af-
Table 1. Selected properties for the virgin NF270 membrane.

\begin{tabular}{ccccc}
\hline Membrane & $\begin{array}{c}\text { MWCO } \\
\left(\mathrm{g} \mathrm{mol}^{-1}\right)\end{array}$ & $\begin{array}{c}\text { Membrane } \\
\text { thickness } \\
(\mathrm{nm})\end{array}$ & $\begin{array}{c}\text { Pure water } \\
\text { permeability } \\
\left(\mathrm{l} \mathrm{m}^{-2} \mathrm{~h}^{-1} \mathrm{bar}^{-1}\right)\end{array}$ & $\begin{array}{c}\mathrm{NaCl} \\
\text { rejection } \\
(\%)\end{array}$ \\
\hline NF270 & $270-300$ & $\begin{array}{c}15-40 \\
(\text { Freger, 2003) }\end{array}$ & 13.6 & $40-60$ \\
\hline
\end{tabular}

fected by a large number of variables such as membrane type, feed water composition (feed concentration of trace organics, $\mathrm{pH}$, and salt balance) and operating conditions. Moreover, detailed characterisation of fouled membranes should be considered as a prerequisite for any investigation aiming to better understand the effects of fouling on membrane surface properties and on resulting rejection behaviour of trace organics.

Most previous studies have investigated removal of trace organics at high feed concentrations $\left(\mathrm{mg} \mathrm{l}^{-1}\right)$ in order to facilitate detection of the trace chemicals in membrane feed and permeate samples. Also, most studies were carried out under constant transmembrane pressure (TMP) since this is often a simpler protocol to implement for laboratory-scale studies. As a result, previous research failed to accurately represent full-scale plants, which usually operate under constant flux and treat lower trace organics concentrations in the feed $\left(\mu \mathrm{g}^{-1}-\mathrm{ng}^{-1}\right)$. It has been observed that filtration at constant flux may result in significantly lower fouling rates, compared to studies conducted at constant TMP (Defrance and Jaffrin, 1999). In this research, the phenomena occurring in NF operation will be studied using environmental concentrations of Organic matter (OM) and trace organics in constant flux mode, as a more realistic approach.

In the current study, the effect of membrane fouling on the rejection of trace organics in conjunction with solute and membrane physicochemical characteristics is assessed. Various types of OM are used to foul the membrane, to investigate the influence of OM nature on the rejection of trace organics. This study will also address the influence of the foulants nature on the temporal changes and properties of the fouled membrane, and their interactions with the physicochemical properties of trace organics.

\section{Materials and methods}

\subsection{NF Membrane and filtration protocol}

A commercially available NF membrane, NF270 (Dow Chemicals) was used in this study. The membrane properties are shown in Table 1. The molecular weight cut off (MWCO) and salt rejection values were provided by the membrane manufacturer. The membrane was rinsed with Milli-Q water for duration of $1 \mathrm{~h}$ prior to use. Then, the virgin membrane 


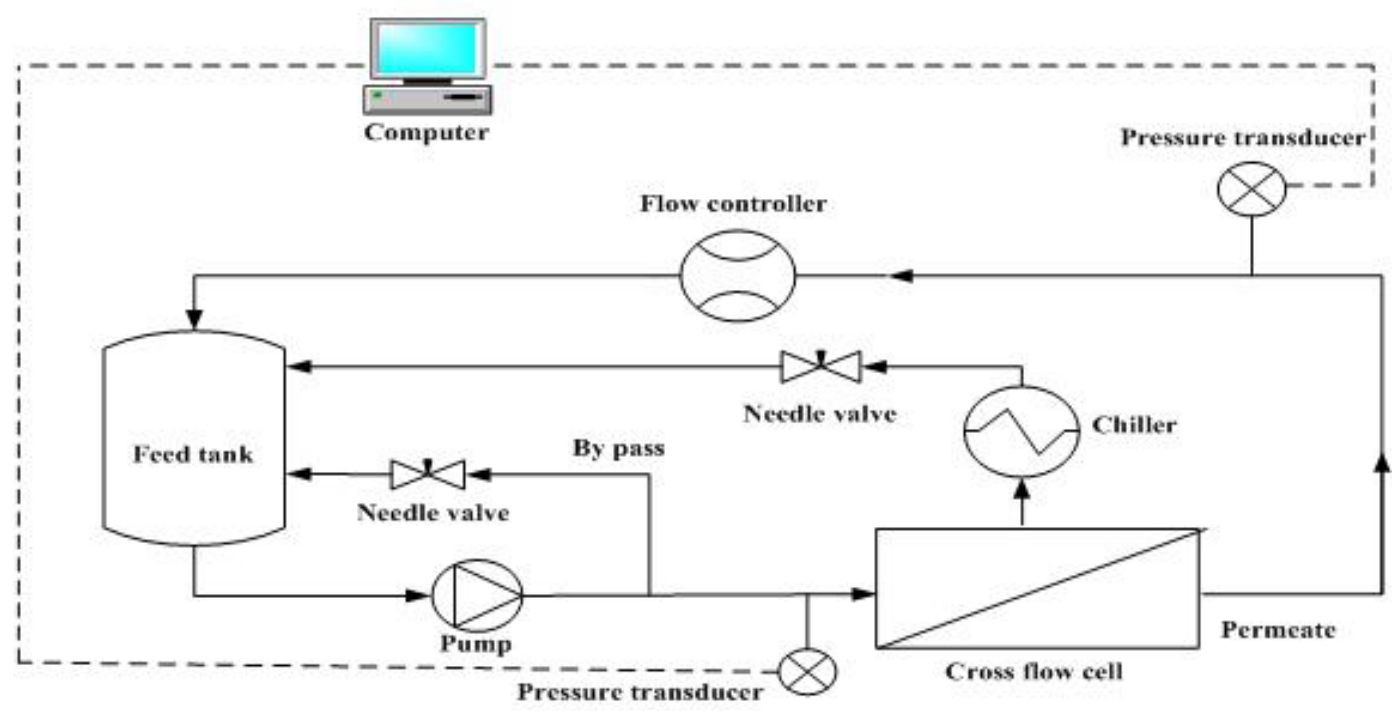

Figure 1. Schematic illustration of the experimental set up.

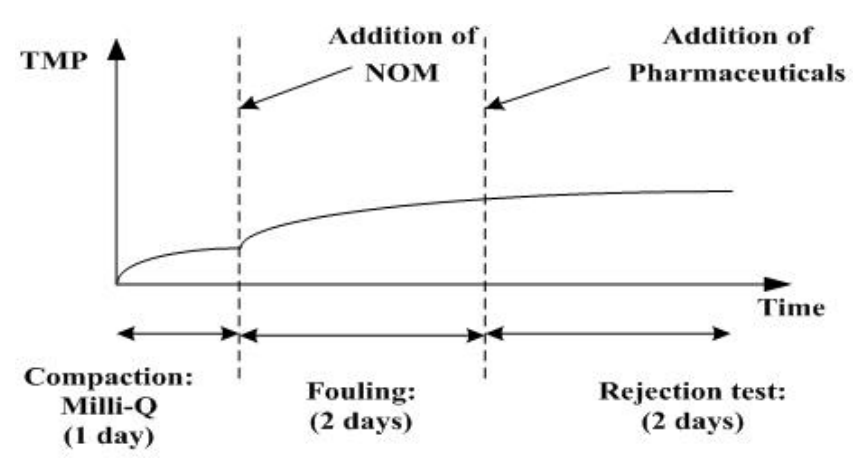

Figure 2. Filtration protocol for compaction, fouling and rejection test.

was characterised in terms of pure water permeability with Milli-Q water.

A bench-scale NF set up was used in this study (Fig. 1). A flat sheet membrane cell with channel dimensions of $12.2 \mathrm{~cm}$ in length, $3.8 \mathrm{~cm}$ in width and $0.3 \mathrm{~cm}$ in height was used to accommodate the membrane active area of $46.4 \mathrm{~cm}^{2}$. In all experiments, the permeate and concentrate were recirculated back to the feed vessel, except when samples were collected for analysis. The feed temperature was maintained at $25 \pm 1{ }^{\circ} \mathrm{C}$ using a stainless steel water cooling system (Grant thermostat).

All experiments in this study were carried out in 3 steps as shown in Fig. 2. In the first step, the membrane was compacted with Milli-Q at 15 bar for $24 \mathrm{~h}$, to allow TMP stabilisation. Then, the membrane was characterised for salt rejection using a $500 \mathrm{mg} \mathrm{l}^{-1} \mathrm{NaCl}$-solution to ensure that the specimen was not damaged or ruptured before or during compaction. In the second step, organic fouling was developed by introducing a synthetic feed solution containing organic foulant, surface water, or MBR effluent to the feed reservoir. Fouling experiments were conducted at applied pressure of 5.5 bar, constant cross-flow velocity of $0.2 \mathrm{~m} \mathrm{~s}^{-1}$ and constant flux of $201 \mathrm{~m}^{-2} \mathrm{~h}^{-1}$ over $48 \mathrm{~h}$. The increase in TMP was monitored to evaluate membrane hydraulic performances. In the third step, the concentrated stock solution of trace organics was spiked in the feed solution to obtain a concentration of $2 \mu \mathrm{g} \mathrm{l}^{-1}$ of each individual compound. Triplicate samples of both feed and permeate streams were taken $(150 \mathrm{ml})$ to determine the statistical variance on the results. Rejection $(R$ in $\%$ ) was defined as indicated in Eq. (1):

$R \%=100 \cdot\left(1-\frac{C_{\mathrm{P}}}{C_{\mathrm{F}}}\right)$

Where $C_{\mathrm{P}}$ and $C_{\mathrm{F}}$ are permeate and feed concentration, respectively. After each experiment, the membrane sample was carefully preserved in dry conditions for subsequent surface characterisation.

\subsection{Membrane characterisation}

Membrane contact angles were measured using a Rame-Hart goniometer (Model 200-F1). Contact angle measurements were performed using the sessile drop technique and Milli$\mathrm{Q}$ water. The average of at least 10 measurements on different locations of the membrane was calculated. Membrane roughness was measured by atomic force microscopy (AFM) with tapping mode in air using a DI3000 microscope (Veeco), also on 10 different locations across the sample $(2 \times 2 \mu \mathrm{m}$ scanning area). Membrane charge (zeta potential) was determined at $\mathrm{pH} 6.5$ in a $1 \mathrm{mM} \mathrm{KCl}$ (Aldrich) background solution using streaming potential equipment (SurPass, Anton 
Table 2. Properties of selected trace organic compounds.

\begin{tabular}{|c|c|c|c|c|c|c|c|}
\hline Compounds & Abbreviation & $\mathrm{MW}\left(\mathrm{g} \mathrm{mol}^{-1}\right)$ & Length (nm) & Width (nm) & Height (nm) & $\mathrm{pKa}^{\mathrm{a}}$ & $\log D(\text { at } \mathrm{pH} 6.5)^{\mathrm{b}}$ \\
\hline \multicolumn{8}{|c|}{ Hydrophilic nonionic } \\
\hline Trimethoprim & TTP & 290 & 1.05 & 0.76 & 0.42 & 7.2 & -0.105 \\
\hline Paracetamol & PCL & 151 & 0.75 & 0.61 & 0.41 & 9.9 & 0.49 \\
\hline Caffeine & $\mathrm{CFN}$ & 193 & 0.75 & 0.67 & 0.41 & 14.39 & -0.07 \\
\hline Sulfamethoxazole & SMX & 253 & 1.03 & 0.59 & 0.41 & 10.39 & -0.105 \\
\hline \multicolumn{8}{|l|}{ Ionic } \\
\hline Diclofenac & $\mathrm{DFN}$ & 318 & 0.89 & 0.83 & 0.42 & 4.18 & 1.75 \\
\hline Ibuprofen & IBF & 206 & 0.90 & 0.61 & 0.42 & 4.41 & 1.64 \\
\hline Naproxen & NPN & 230 & 0.99 & 0.62 & 0.41 & 4.84 & 1.33 \\
\hline \multicolumn{8}{|c|}{ Hydrophobic nonionic } \\
\hline Carbamazepine & $\mathrm{CBZ}$ & 236 & 0.87 & 0.70 & 0.35 & 13.49 & 1.89 \\
\hline Risperidone & RPD & 410 & 1.47 & 0.72 & 0.42 & 7.89 & 1.475 \\
\hline Fluoxetine & FLX & 309 & 1.12 & 0.70 & 0.42 & 10.05 & 1.17 \\
\hline Bisphenol A & BPA & 228 & 0.92 & 0.66 & 0.41 & 9.73 & 3.63 \\
\hline
\end{tabular}

a Available data calculated using Sparc calculator.

${ }^{\mathrm{b}}$ Available data calculated using for acids, and bases $\log D_{(\mathrm{pH})}=\log P-\log \left(1+10^{\mathrm{pH}-\mathrm{pKa} \mid}\right)$,

Paar). Membrane samples were dried in a dessicator $24 \mathrm{~h}$ before roughness, streaming potential and contact angle measurements.

\subsection{Trace organic compounds and analysis}

Target organic solutes were selected to represent a wide range of physicochemical properties and were categorised according to their acid dissociation constants (pKa) and Log octanol-water distribution ratio $(\log D)$ values. The physicochemical properties of the selected compounds are presented in Table 2. The hydrophobicity of solutes can be correlated and quantified with the logarithm of the octanol-water partitioning coefficient $\left(\log K_{\text {ow }}\right)$. The $\log D$ value is similar to $\log K_{\text {ow }}$, but also considers the ionic speciation of the compound (Nghiem and Coleman, 2008). In previous studies, compounds with $\log D$ smaller than 1 and greater than 3 have been defined as highly hydrophilic and hydrophobic, respectively. However, uncertainties exist for compounds with $\log D$ values between 1 and 3 (Wells, 2006). In this research, solutes with $\log D$ below 1 were ranked as hydrophilic, between 1 and 3 as intermediate hydrophobic and above 3 as highly hydrophobic compounds.

All of the trace organic compounds were of analytical grade and were purchased from Supelco. A concentrated stock solution was prepared in methanol and was stored at $4{ }^{\circ} \mathrm{C}$ in an amber glass container. The concentrations of trace organic solutes in feed and permeate samples were analysed by high performance liquid chromatography/tandem mass spectrometry (HPLC-MS/MS) using a method adapted from the literature (Vanderford and Snyder, 2006). These analy- ses were undertaken with an Agilent HPLC 1200 series coupled to an Applied Biosystems API 4000 triple quadrupole mass spectrometer. Before the analysis, solid phase extraction (SPE) was carried out using $1 \mathrm{~g}$ of hydrophilic-lipophilic balance (HLB) solid phase material (Bakerbond Polar Plus) filled in a $6 \mathrm{ml}$ polyethylene cartridge. Total organic carbon (TOC) analysis was conducted using a Shimatzu800 TOC analyser. The confidence level of the trace organics analysis was assessed using three replicates of filtration of L-lysine. The confidence level (i.e., the relative error on the results) of the NF experiments is reflected as standard deviation (STD). The calculated standard error (STD \%) from triplicate measurements were used for all experiments in this study.

\subsection{Feed water characteristics and analysis}

The fouling experiments were carried out with different model organic foulants, including humic acid (Aldrich), Llysine (Aldrich), alginic acid (Ajax Chemicals) and Suwannee River Humic Acid (International Humic Substances Society). The feed solution also contained a buffer solution containing $\mathrm{KH}_{2} \mathrm{PO}_{4} 0.1 \mathrm{M}$ (Aldrich) and $\mathrm{NaOH} \mathrm{0.1} \mathrm{M} \mathrm{(Aldrich)}$ to maintain the solution $\mathrm{pH}$ at 6.5. Sodium azide (Riedel-de Haën) was added at a concentration of $0.02 \%$ by weight to prevent growth of bacteria, which could result in the development of biofilm on the membrane surface. As a result, the potential impact of biofilm in NF rejection was not considered within the scope of this study. The chemicals used for this project were of analytical grade without any further modification. Milli-Q water was provided via Milli-Q system by

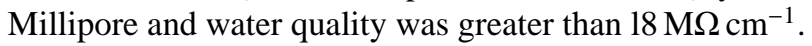


Table 3. Characterisation of the feed waters by LC-OCD.

\begin{tabular}{lcccccr}
\hline & Humic acid & Alginic acid & L-Lysine & SRHA & Surface water & MBR permeate \\
\hline Organic carbon fraction (\%) & & & & & & \\
\hline Bio-polymers $^{\text {a }}$ & n.q. & 100 & 100 & n.q. & 3.1 & 11.1 \\
Humic Subst. (HS) $_{\text {Building Blocks }}^{\text {b }}$ & 67.0 & n.q. & n.q. & 80.2 & 33.1 & 32.4 \\
Neutral LMW organics & 14.8 & n.q. & n.q. & 8.0 & 17.3 & 16.6 \\
Acidic LMW organics Acids & 18.2 & n.q. & n.q. & 11.8 & 12.5 & 39.9 \\
\hline Average molecular weight $\left(\mathrm{g} \mathrm{mol}^{-1}\right)$ & n.q. & n.q. & n.q. & 34.0 & 0.0 \\
\hline & 961 & 8291 & 554 & 1033 & & \\
\hline
\end{tabular}

${ }^{\mathrm{a}}$ Biopolymers $=$ polysaccharides, proteins, aminosugars; ${ }^{\mathrm{b}}$ Building Blocks = breakdown products of humics; n.q. Not quantifiable $(<1$ ppb calculated $)$

Each fouling solution was prepared by dissolving individual foulant in the electrolyte solution described above to make up a total organic carbon (TOC) concentration of $5 \mathrm{mg} \mathrm{l}^{-1}$. Since the experiments were conducted in constant flux mode, the same amount of TOC was delivered to the membrane surface for a given volume of permeate in each experiment. Hence, 151 of solutions filtered in recirculation mode during $96 \mathrm{~h}$, resulted in TOC delivered of $0.01 \mathrm{mg}$ per $\mathrm{cm}^{2}$ of membrane, calculated using Eq. (2).

Delivered TOC $\left(\frac{\mathrm{mg}}{\mathrm{cm}^{2}}\right)=V \cdot \frac{C}{A}$

Where $V(\mathrm{l})$ is the permeate volume collected during filtration, $C\left(\mathrm{mg} \mathrm{l}^{-1}\right)$ is the feed TOC concentration and $A\left(\mathrm{~cm}^{2}\right)$ is the membrane surface area. However, it is noteworthy that a similar amount of DOC delivered to the membrane for different foulants does not necessarily result in similar fouling extents.

In addition to the synthetic solutions described above, untreated surface water (Woronora dam, NSW) and an anaerobic membrane bioreactor (MBR) permeate (pilot plant, UNSW Water Research Centre) were used. The TOC and pH of these feed waters were adjusted to match the model solutions. Sodium azide was also added to minimise the growth of biofilm. The relative impact of the presence of inorganics in the effluent was not studied in this work.

The dissolved organics in both model and real feed solutions were characterised by dissolved organic carbon (DOC) Labor Model 8 liquid chromatography-organic carbon detection (LC-OCD). During LC-OCD analysis, the dissolved organics were separated into the chromatographable dissolved organic carbon (CDOC) and non chromatographable dissolved organic fractions (NDOC), depending on the affinity of the DOC for the resin (HW50S). The NDOC fractions may be approximately described as the lipid based compounds greater than $1 \mu \mathrm{m}$ in size. The CDOC portion was fractionated into five major fractions, as shown in Table 3. The organics were characterised based on the MW, also taking the ionic and hydrophobic interactions into account. Separation was based on the steric interaction of the DOC with the column over the wide range of MW.

\section{Results and discussions}

\subsection{Rejection of trace organic compounds by virgin membrane}

The rejection of the mixture of selected pharmaceuticals in Milli-Q water was determined in order to obtain the baseline rejection values of the virgin membrane during $48 \mathrm{~h}$ filtration. In this initial experiment, the impact of the presence of trace organic compounds on the membrane hydraulic performances was also assessed.

In constant flux operation, an increase in TMP generally indicates the occurrence of fouling. During filtration of the solution containing Milli-Q water and trace organics, no significant TMP increase was observed. This indicates that TMP reached a steady-state during the initial $24 \mathrm{~h}$ compaction period, and the stable trend of TMP after the compaction suggests that the trace organics did not foul the membrane. This was expected because of the very low concentration of the trace organics used in these experiments. It was also observed that the rejection of all trace organics reached a steady-state value within the first $4 \mathrm{~h}$ of filtration.

\subsubsection{Adsorption onto NF membrane}

For most of the trace organic chemicals in this study, the rejection levels by the virgin membrane reached stable value within the first hour of filtration. The concentrations of these compounds in the feed solution and permeate did not change significantly during the remaining of the filtration and thus, little adsorption on NF was expected. Amongst the hydrophobic nonionic trace organic solutes in this study, only bisphenol A was observed to exhibit different rejection behaviour. Figure 3 shows the rejection of bisphenol A by the virgin membrane during $48 \mathrm{~h}$ of filtration. Bisphenol A was 


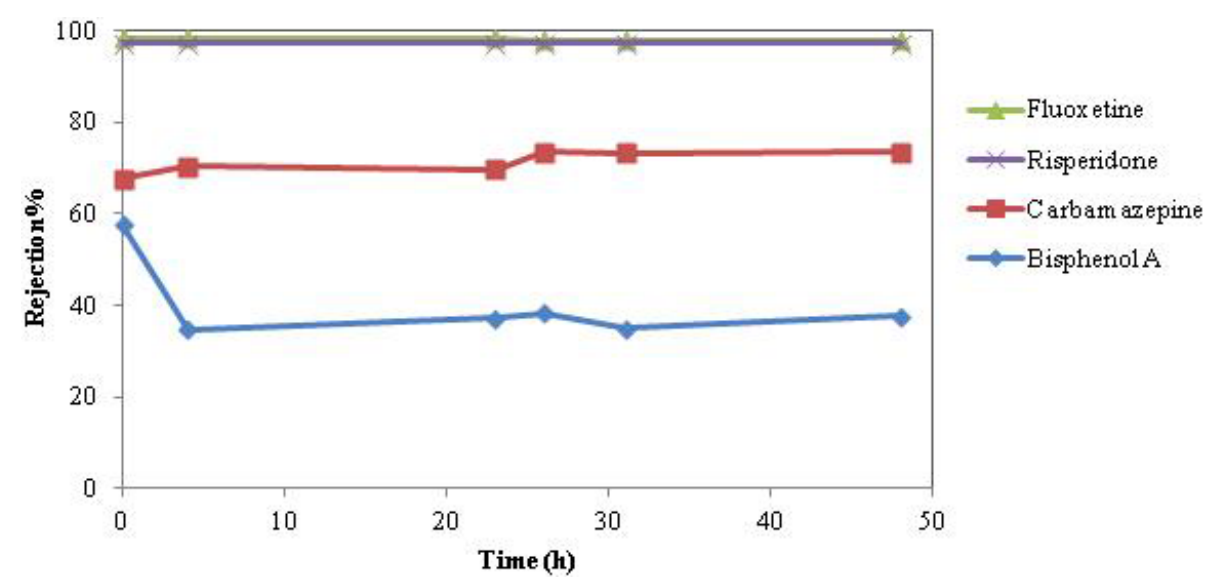

Figure 3. Temporal changes for rejection of fluoxetine, risperidone, carbamazepine and bisphenol A rejection by new NF270 membrane.

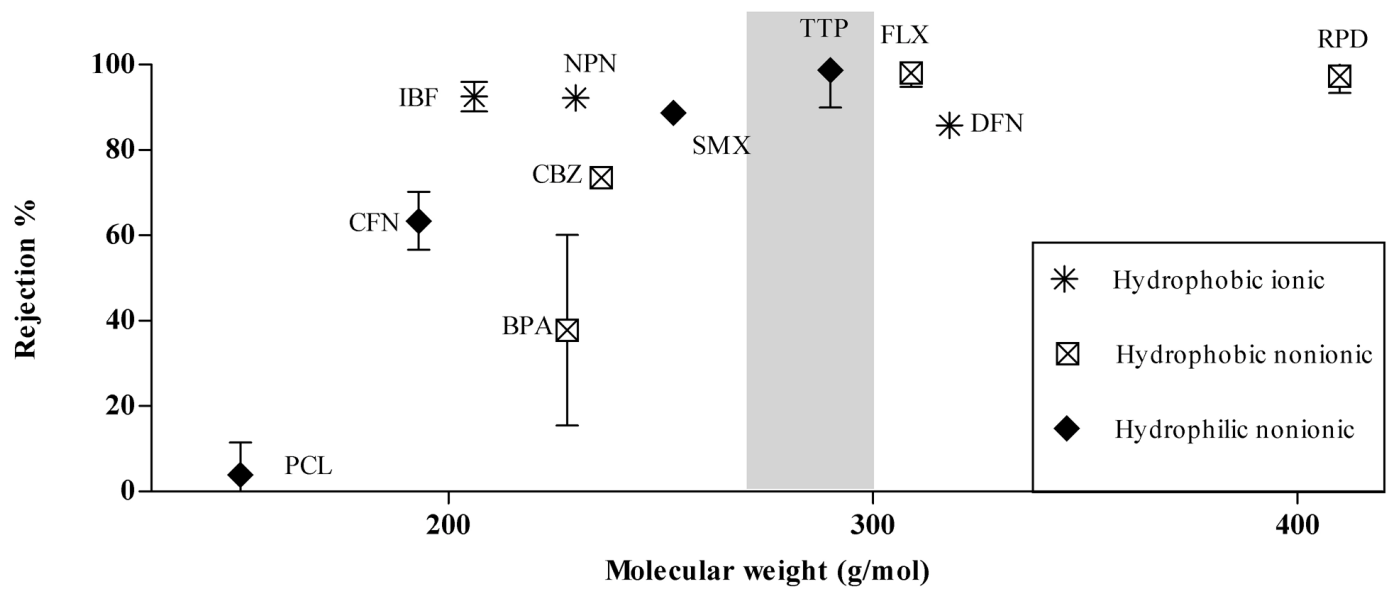

Figure 4. Rejection of trace organic compounds vs. their molecular weights. The high-lighted area indicates the MWCO of the NF270 membrane.

rejected at $60 \%$ in the beginning of filtration. The high initial retention of bisphenol A was then followed by a sharp decline to $35 \%$. The rejection of bisphenol A stabilised during the first $4 \mathrm{~h}$ of the experiment. In a previous study, it was hypothesised that high initial rejections of hydrophobic solutes followed by a sharp decline to a much lower stabilised rejection value were due to adsorption on the membrane (Kimura et al., 2003a). The adsorption of trace organics to the membrane was reported to be mainly affected by hydrophobic interactions for aromatic pesticides (Kiso et al., 2001). In this experiment, bisphenol A featured the highest $\log D$ value amongst the hydrophobic solutes and thus, exhibited a higher propensity to adsorb onto the membrane. Indeed in another study, considerable static adsorption of both bisphenol A and risperidone onto NF270 was already reported. However, because of its large MW $\left(410 \mathrm{~g} \mathrm{~mol}^{-1}\right)$, risperidone was not expected to partition as easily as bisphenol A $\left(228 \mathrm{~g} \mathrm{~mol}^{-1}\right)$. This was confirmed by the stable rejection values observed for risperidone.

\subsubsection{Rejection of trace organics by virgin NF membrane}

The steady-state rejection values of the three groups of compounds after $48 \mathrm{~h}$ filtration by the virgin NF270 membrane are shown in Fig. 4. The trace organics in each group were plotted according to their molecular weight.

\subsubsection{Negatively charged ionic compounds}

The negatively charged ionic solutes were efficiently removed at more than $90 \%$, as the result of electrostatic repulsion with the virgin membrane. According to YangaliQuintanilla et al., the observed retention of naproxen and ibuprofen by a NF200 membrane was due to the combined influence of steric hindrance and electrostatic repulsion (Yangali-Quintanilla et al., 2009). However, in the current study, no significant relationship between the compounds MW and their rejection was observed. As such, it can be hypothesised that steric hindrance was not significant, and the main rejection mechanism for the negatively charged 
Table 4. Summary of rejection mechanisms observed for the trace organic compounds (MW $<270 \mathrm{~g}$ mol $^{-1}$ ) by virgin NF270.

\begin{tabular}{|c|c|c|c|c|}
\hline Type of compounds & Steric hindrance & Electrostatic repulsion & $\begin{array}{l}\text { Solute membrane } \\
\text { affinity }\end{array}$ & dominant mechanism \\
\hline Ionic compounds & - & $\begin{array}{l}\text { Higher rejection indepen- } \\
\text { dent of the solutes MW }\end{array}$ & $\begin{array}{l}\text { Lower rejection of } \\
\text { the more hydropho- } \\
\text { bic solutes }\end{array}$ & $\begin{array}{l}\text { Electrostatic } \\
\text { repulsion }\end{array}$ \\
\hline $\begin{array}{l}\text { Hydrophilic nonionic } \\
\text { compounds }\end{array}$ & $\begin{array}{l}\text { Partial rejection depend- } \\
\text { ing on solutes MW }\end{array}$ & - & - & Steric hindrance \\
\hline $\begin{array}{l}\text { Hydrophobic nonionic } \\
\text { compounds }\end{array}$ & $\begin{array}{l}\text { Partial rejection depend- } \\
\text { ing on solutes MW }\end{array}$ & - & $\begin{array}{l}\text { Lower rejection of } \\
\text { solutes with higher } \\
\log D\end{array}$ & $\begin{array}{l}\text { Steric hindrance/ } \\
\text { solute-membrane } \\
\text { affinity }\end{array}$ \\
\hline
\end{tabular}

ionic compounds by the virgin membrane used in this study (NF270) was electrostatic repulsion. One notable exception was diclofenac, which was slightly less well rejected than the other negatively-charged solutes. This can be explained by the physicochemical properties of diclofenac, which features the highest $\log D$ value in this group. As mentioned previously, solutes with high $\log D$ are considered more hydrophobic and thus tend to adsorb and partition into the membrane matrix. As a result, lower rejection values are expected, since the compounds are eventually released into the permeate (Kimura et al., 2003b). In the case for diclofenac, the non-electrostatic affinity between the compound and the membrane offsets its potential rejection by electrostatic repulsion.

\subsubsection{Nonionic compounds}

\section{Hydrophobic compounds}

Rejection of hydrophobic nonionic compounds by the NF270 membrane varied significantly from 38 to $98 \%$. As expected, compounds with larger MW were more efficiently removed (>90\%), compared to the smaller molecules (Fig. 4).

Although fluoxetine and risperidone seem to be neutral, according to their single $\mathrm{pKa}$ value at $\mathrm{pH}$ 6.5, their full association indicated that they can form positively charged ionic species as well. On the other hand, both risperidone and fluoxetine are relatively large compounds and thus, the overwhelming effect of size exclusion overcomes the less significant sorption and electrostatic attraction between them and the membrane.

It was also observed that the difference between the rejection of compounds with similar MW and below the MWCO of the membrane was significant. For example, bisphenol A and carbamazepine rejection values were expected to be in the same range, based on their MW, whereas they were rejected at 38 and $73 \%$, respectively. As can be seen in Table 2, bisphenol A features higher $\log D$ value and thus more hydrophobic than carbamazepine (3.63 compared to 1.89 ). The results indicate that compounds with higher $\log D$ val- ues, but which are also too small to be mainly rejected via steric hindrance, feature lower rejection levels. This is due to the higher affinity between the more hydrophobic compounds and the hydrophobic membrane matrix: hydrophobic solutes partition into the membrane, and consequently diffuse more readily through the membrane. Once again, there was no significant relationship between the rejection of large solutes (i.e., MW above $300 \mathrm{~g} \mathrm{~mol}^{-1}$ ) and their $\log D$ value.

\section{Nonionic hydrophilic compounds}

Rejection values of non-ionic hydrophilic solutes by the virgin membrane ranged from 4 to $99 \%$, and were clearly dependent on their MW. Trimethoprim, the solute with the largest MW $\left(290 \mathrm{~g} \mathrm{~mol}^{-1}\right)$ in this group, was removed almost completely (99\%). Paracetamol, on the other hand, was only slightly rejected by the NF270 membrane, due to the small MW of this compound $\left(151 \mathrm{~g} \mathrm{~mol}^{-1}\right)$. These results suggest that a major rejection mechanism for nonionic hydrophilic compounds remained size exclusion. This is consistent with the findings of Yangali-Quintanilla et al., who attributed rejection of nonionic compounds to the sieving phenomenon (Yangali-Quintanilla et al., 2009). Table 4 shows the summary of the observed rejection mechanisms of the target compounds by the virgin membrane.

\subsection{Rejection of trace organic compounds by fouled membranes}

\subsubsection{Characterisation of the fouled membrane}

Membrane fouling experiments were conducted using different organic foulants, under constant flux operation and constant TOC delivery rate. The characteristics for the new and fouled membrane are presented in Table 5.

TMP increase and conductivity rejection for new and fouled membranes were used to confirm the occurrence of fouling and concentration polarization within the fouling layer. The changes in membrane performance after fouling varied noticeably for the different macromolecules despite 
Table 5. Characteristics for compacted and fouled NF270 in terms of TMP increase, salt rejection, roughness, contact angle and zeta potential.

\begin{tabular}{lccccc}
\hline Experiments & $\begin{array}{c}\text { TMP increase } \\
(\%)\end{array}$ & $\begin{array}{c}\text { Conductivity } \\
\text { rejection }(\%)\end{array}$ & $\begin{array}{c}\text { Roughness } \\
(\mathrm{nm})\end{array}$ & $\begin{array}{c}\text { Contact } \\
\text { angle }\left({ }^{\circ}\right)\end{array}$ & $\begin{array}{c}\text { Zeta potential } \\
\text { at pH 6.5 }(\mathrm{mV})\end{array}$ \\
\hline New membrane (compacted) & - & 59.2 & $20 \pm 4$ & $58 \pm 3$ & -21 \\
HA & 18 & 56.3 & $25 \pm 1$ & $57 \pm 5$ & -17 \\
L-Lysine & 10 & 67.6 & $61 \pm 1$ & $60 \pm 5$ & -22 \\
Alginate & 13 & 60.5 & $13 \pm 6$ & $36 \pm 4$ & -48 \\
SRHA & 5 & 53.7 & $27 \pm 3$ & $35 \pm 3$ & -18 \\
Surface water & 6 & 30.9 & $31 \pm 4$ & $78 \pm 4$ & -13 \\
MBR permeate & 7 & 24.6 & $10 \pm 3$ & $66 \pm 2$ & -22 \\
\hline
\end{tabular}

the constant amount of TOC delivered to membrane in all experiments. For the real water types, the changes in conductivity rejection were even more significant. The normalized TMP generally increased by 5 to $18 \%$ after $96 \mathrm{~h}$ of filtration for the different foulants. This indicates that the extent of fouling was significant but not severe.

Increased TMP and improved conductivity rejection after fouling was observed for the model foulants humic acid, Llysine and alginate. This indicated that a compacted fouling layer was formed by these foulants, acting as an additional separation barrier.

On the other hand, for some foulants, fouling resulted in a small TMP increase and a considerable decrease in conductivity rejection. This was probably due to the formation of a rather porous cake layer by these foulants. The decrease in salt rejection in the presence of a porous cake layer is probably caused by CECP: the concentration polarization within a porous fouling is higher than in the bulk solution (for a virgin membrane) due to entrapment of small solutes within the cake layer, which hinders their back-diffusion into the bulk solution. This was already observed in previous studies, where it was reported that membrane fouling by NOM resulted in low hydraulic resistance and thus porous cake layer (Li and Elimelech, 2004; Nghiem and Hawkes, 2009; Hoek and Elimelech, 2003).

The characterisation of the fouled membranes confirmed that their surface properties were significantly different, compared to the virgin membrane. The virgin membrane was negatively charged $(-21 \mathrm{mV})$ at $\mathrm{pH} 6.5$, whereas fouled membranes generally demonstrated significant variations from that value ( -13 to $-48 \mathrm{mV})$. The change in membrane hydrophobicity was dependent on the properties of the fouling material. The roughness data indicated that the smooth NF270 membrane $(20 \mathrm{~nm})$ became noticeably rougher after fouling ( 25 to $61 \mathrm{~nm}$ ), except when being fouled with alginate and MBR permeate (13 and $10 \mathrm{~nm}$, respectively). Alginate and MBR permeate both created a "gel-like" fouling layer (i.e., tipically formed by extracellular polymeric substances). Therefore, the roughness for this specimen measured with AFM (in dry mode) might not represent the real surface morphology of alginate and MBR fouling in wet conditions.

\subsubsection{Rejection of ionic compounds by fouled membranes}

The temporal changes in rejection of diclofenac, naproxen and ibuprofen during the different fouling runs were monitored. The rejection values of all three ionic compounds were observed to be relatively stable and constant during filtration, indicating that the ionic solutes did not significantly adsorb onto the fouling layers. This is probably due to the electrostatic repulsion between the ionic solutes and the negatively-charged membrane surface. As these solutes cannot approach the membrane surface, hydrophobic interactions (adsorption) between the membrane and these solutes are limited (Verliefde et al., 2009).

The rejection levels for the negatively-charged hydrophobic compounds by fouled membranes are shown in Fig. 5. Generally, the rejection of these compounds did not vary significantly when the membrane was fouled, except for naproxen with the SHRA- and surface water-fouled NF270. Rejection of naproxen by these membranes significantly decreased, compared to the clean membrane.

Since the main rejection mechanism for ionic solutes was expected to be electrostatic repulsion, no significant correlation between the rejection and the MW of these solutes was expected. Fouling generally reduced the membrane surface charge (except for the alginate-fouled membranes), and thus electrostatic repulsions between the fouled membranes and the ionic solutes was expected to be lower. This was, however, not consistent with the slight increase in rejection of diclofenac when the membranes became fouled, nor with the stable rejections of the other ionic solutes.

The higher rejection of diclofenac after fouling can be explained by the increased overall charge density of the fouled membranes. Even though the membrane charge decreased, the roughness of the fouled membranes was higher (i.e., larger membrane surface area). The combined effect of surface morphology and membrane charge, on the removal of 


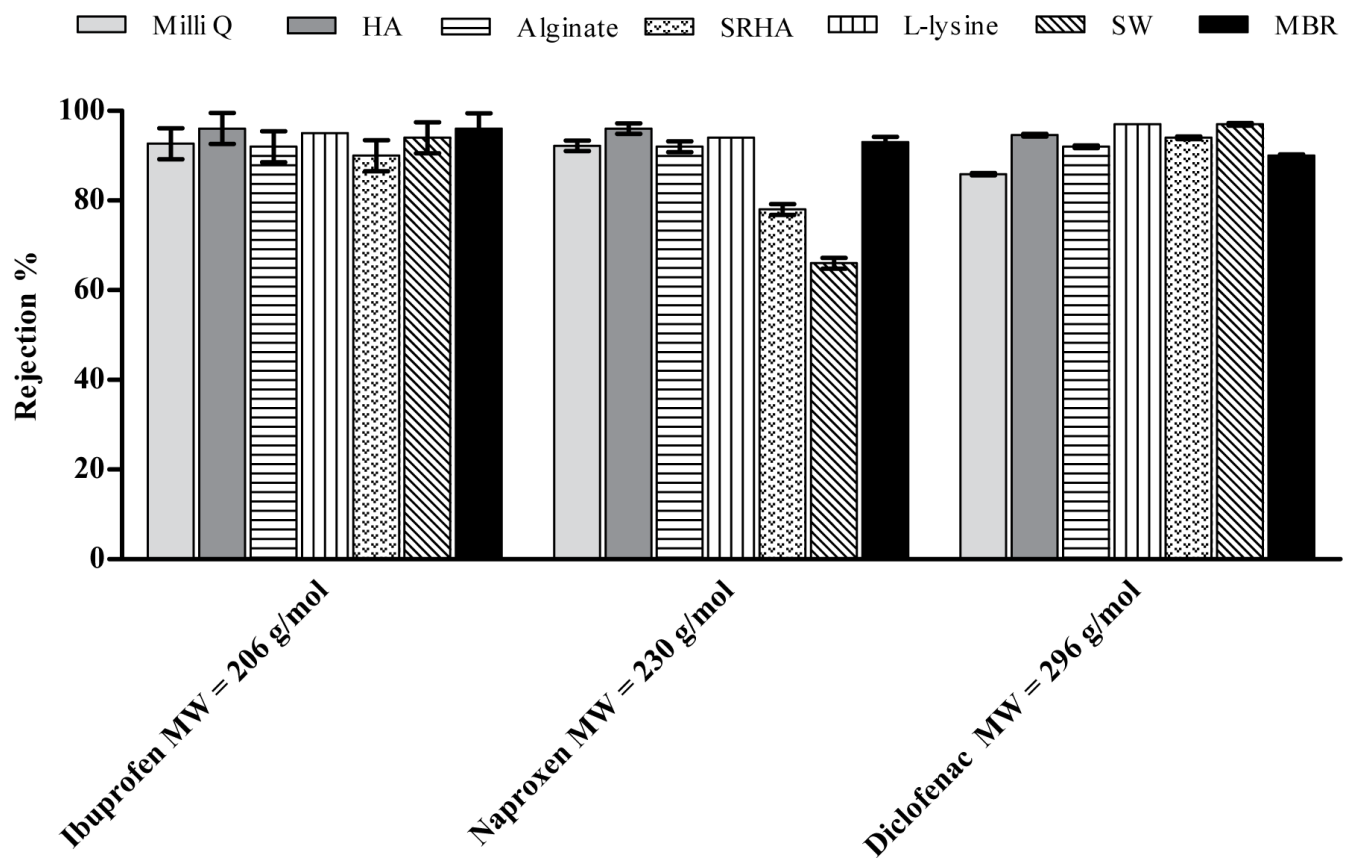

Figure 5. Rejection of hydrophobic ionic compounds by membranes fouled by various organic matters.

ionic trace organics has been reported in a previous study (Verliefde et al., 2009). For rough membranes, negativelycharged solutes that are forced into the crevices of the rough fouling layer, are surrounded by negative charges, resulting in an increase in electrostatic repulsion, even though the surface charge is lower. As discussed previously, protein- and surface-water-fouled membranes were the roughest, which enhanced the removal of diclofenac for these membranes more significantly.

For the other two ionic compounds, however, this increase of rejection with increasing surface roughness was not observed. In addition, no correlation between rejection and the characteristics of fouled membranes was observed.

\subsubsection{Nonionic hydrophobic compounds}

The rejection levels of the hydrophobic solutes by new and fouled membranes after $48 \mathrm{~h}$ of filtration time are shown in Fig. 6. Risperidone, carbamazepine and bisphenol A were rejected in increasing order, according to their MW. This was already observed in the experiment with Milli-Q water.

Fouling generally reduced the removal of the non-ionic hydrophobic trace organics. For risperidone and fluoxetine, the fouled membrane surface charge can also be responsible for the decreased rejection, since the negatively charged compounds removal indicated a higher negative charge density on the membrane. Theoretically, higher negative charge leads to a decrease in rejection of positively charged solutes (Verliefde et al., 2009).

As shown in Fig. 6, the extent of the decrease in rejection of hydrophobic nonionic compounds was different for each foulant. The variation in rejection by different foulants was due to the different characteristics of these foulants such as organic carbon fractions with different size, hydrophobicity and charge. According to the results of the LC-OCD characterisation, the DOC in the surface water comprised organic matter with a vast range of MW, preventing efficient stacking of the foulant, and thus resulting in a relatively loose cake layer. The gradual increase in concentration of solutes in the porous cake layer leads to a decrease in their removal (Elimelech and $\mathrm{Ng}, 2004)$.

To investigate the hydrophobic interactions between the solutes and the different foulants, the rejection of the solutes was plotted against the fouled membrane contact angle values (e.g., for risperidone in Fig. 7). Rejection of hydrophobic nonionic compounds by the fouled membranes generally correlated positively with the contact angle of these fouled membranes, except for carbamazepine. This is in contradiction with the expected lower rejection where the compounds presented higher affinity with the surface. Interestingly in this case, the membranes were fouled and the measured contact angle represented the hydrophobicity of the foulant, rather than those of the membrane surface. Therefore, it can be hypothesised that although fouling generally decreased the rejection level of hydrophobic compounds, the extent of this decrease was less severe for more hydrophobic solutes. This was most likely due to the adsorption of hydrophobic solutes onto the foulants in the feed. In a previous study, CECP and adsorption (to the foulants) were found to be two counteractive mechanisms influencing the rejection of hydrophilic nonionic trace organics (Hajibabania et al., 2011). 


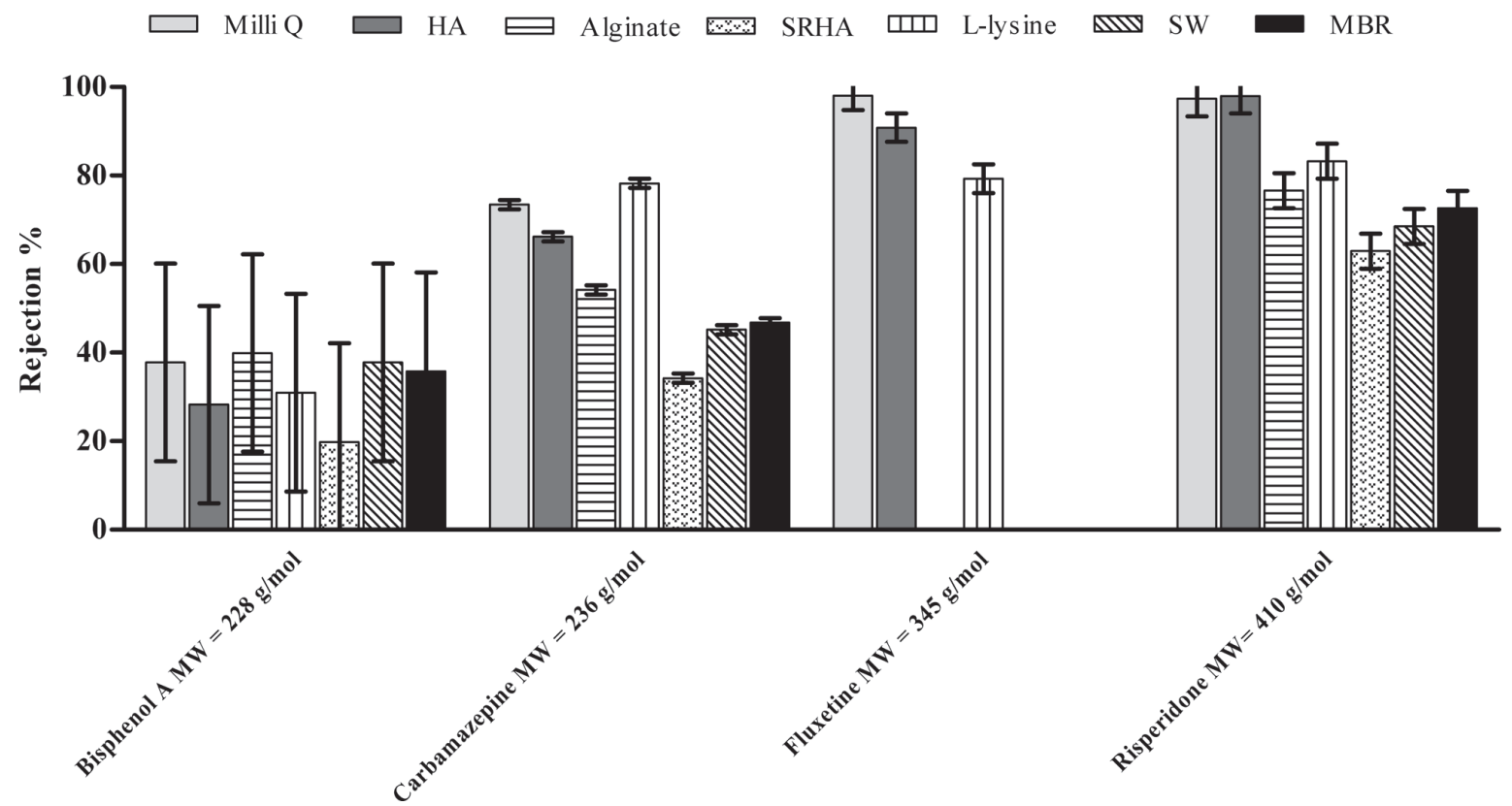

Figure 6. Rejection of hydrophobic nonionic compounds by different fouled membranes.

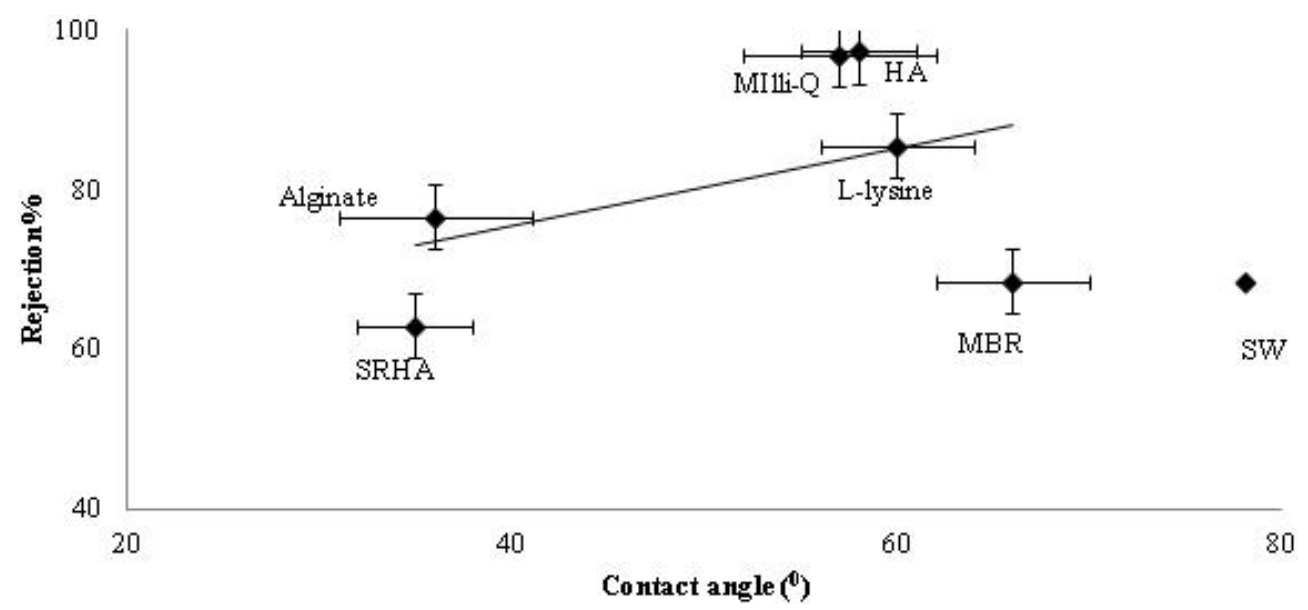

Figure 7. Rejection of risperidone by HA, alginate, lysine, SRHA and surface water fouled NF270 vs. fouled membranes contact angle.

However, the rejection of risperidone and surface water fouled membrane contact angle were an anomaly which might be due to more severe CECP. No significant relationship between rejection and surface roughness of the fouled membrane was observed.

\subsubsection{Nonionic hydrophilic compounds}

The effect of fouling on rejection efficiencies of these compounds was more pronounced compared to the hydrophobic solutes. The rejection efficiencies of the nonionic hydrophilic solutes by new and fouled membranes are shown as a function of their MW in Fig. 8. As can be seen, fouling generally reduced the removal of trace organics, except for paraceta- mol. The striking increase in paracetamol rejection with alginate fouled membrane observed here was not confirmed by previous studies (Hajibabania et al., 2011), and can be the result of an unexpected manipulation error.

Paracetamol thus showed different rejection behaviours compared to the other solutes, which again was due to its small size. For paracetamol alone, fouling enhanced size exclusion, with the extent of the increase in rejection varying depending on the foulant. The largest increases in rejection for paracetamol were observed for the surface water and MBR permeate-fouled membranes, i.e., the foulants with the largest fraction of low MW organic carbon fractions. 


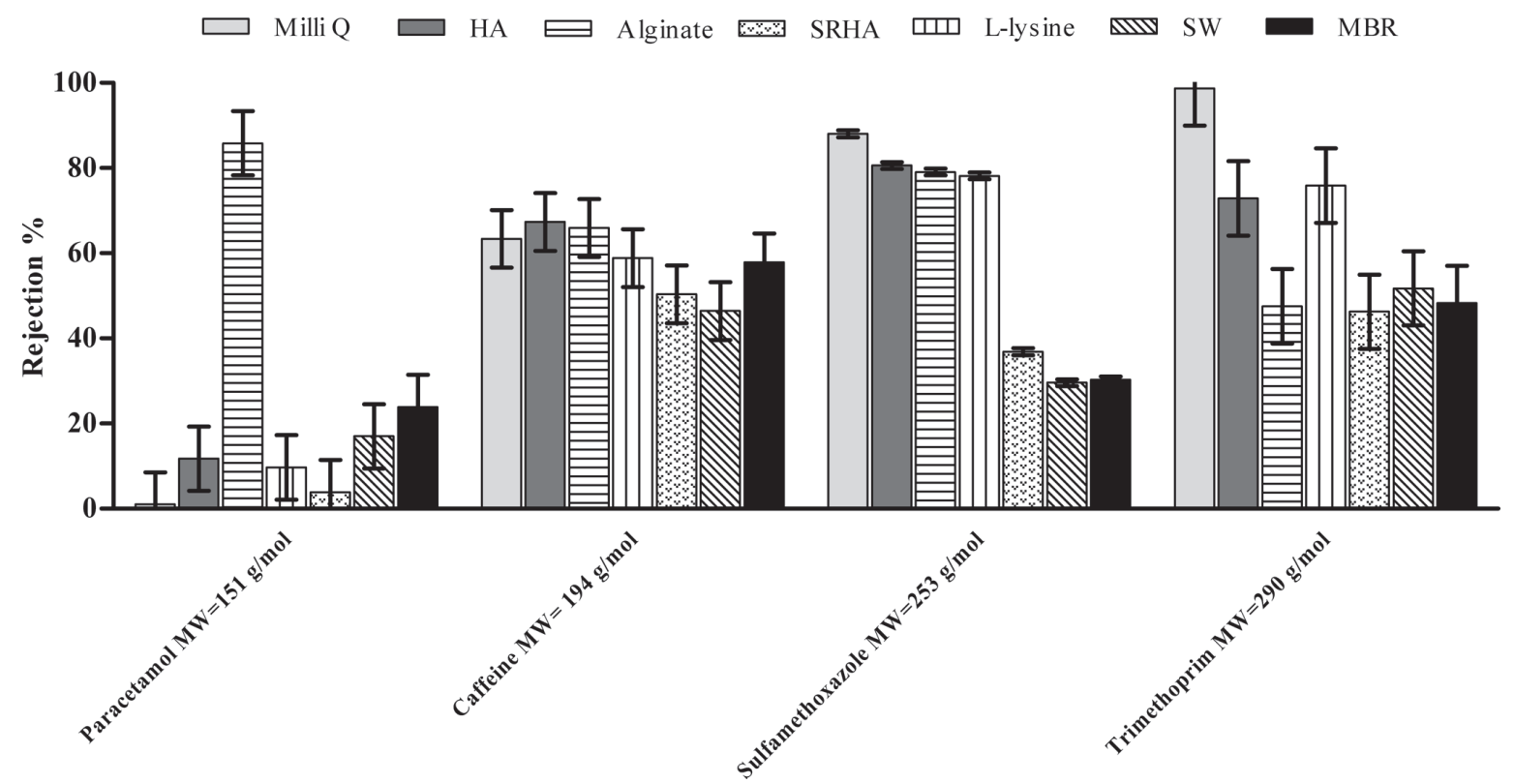

Figure 8. Rejection of hydrophilic nonionic compounds by new and fouled membranes.

Trimethoprim, which was the largest solute in this group, experienced a significant decrease in rejection from 98 to $46 \%$ after membrane fouling. This indicates that the effect of CECP on rejection was more pronounced for larger solutes (since these solutes experienced a more significant hindered back-diffusion).

Porous fouling structures enhanced the occurrence of CECP, and consequently lead to increased transport of solutes through the membrane. This decrease due to severe CECP was most significant for SRHA and surface water fouling layers. Humic acid and lysine fouling layers, on the other hand, decreased the rejection of trace organics less than the other OM used in this study. Both foulants resulted in a higher TMP increase and conductivity rejection, which indicates that they form closely-stacked fouling layers. Apparently, the further size exclusion (sieving effect) was more pronounced than the CECP effect for these foulants.

To investigate the effect of fouled membrane characteristics on removal of nonionic hydrophilic compounds, the rejection of these solutes was plotted against the roughness and contact angles of the fouled membranes. There was no linear relationship observed between the rejection of hydrophilic nonionic compounds and membrane surface roughness and hydrophobicity (data not presented here). Therefore, size exclusion still seems to be the most important mechanism for rejection of hydrophilic solutes, with CECP playing an important role in the rejection of trace organics by fouled membranes.

\section{Conclusions}

In this study, both synthetic and real waters containing organic matters were used to simulate membrane fouling and to assess the impact of fouling on the rejection of trace organics by NF membrane. The well-controlled environment used in this study allowed a detailed assessment of the relative contribution of different organic foulants. It can be concluded that the effect of fouling on removal of trace organics was more pronounced for nonionic compounds, as they can approach and enter the fouling layer, in contrast to ionic solutes, which tend to be repelled by the negatively-charged fouling.

Porous fouling layers resulted in more severe CECP and lower rejections of nonionic solutes. The similar rejection trends obtained for hydrophobic and hydrophilic compounds confirmed the influence of CECP. No clear correlation between rejection by fouled membranes and parameter used to describe surface properties was observed. However, the combination of two or more parameters (such as roughness and charge and the concept of charge density) could be used to explain the observed variations in rejection.

Acknowledgements. The authors would like to thank ARC for the funding of this project. Dow Water \& Process Solutions is also thanked for providing membrane samples.

Edited by: J. Verberk 


\section{References}

Bellona, C., Drewes, J. E., Xu, P., and Amy, G.: Factors affecting the rejection of organic solutes during $\mathrm{NF} / \mathrm{RO}$ treatment a literature review, Water Res., 38, 2795-2809, 2004.

Bolong, N., Ismail, A. F., Salim, M. R., and Matsuura, T.: A review of the effects of emerging contaminants in wastewater and options for their removal, Desalination, 239, 229-246, 2009.

Boussu, K., Vandecasteele, C., and Van der Bruggen, B.: Relation between membrane characteristics and performance in nanofiltration, J. Membrane Sci., 310, 51-65, 2008.

Bowen, W., Doneva, T., and Stoton, J.: Protein deposition during cross-flow membrane filtration: AFM studies and flux loss, Colloid. Surface. B, 27, 103-113, 2003.

Comerton, A. M., Andrews, R. C., and Bagley, D. M.: The influence of natural organic matter and cations on the rejection of endocrine disrupting and pharmaceutically active compounds by nanofiltration, Water Res., 43, 613-622, 2009.

Defrance, L. and Jaffrin, M. Y.: Comparison between filtrations at fixed transmembrane pressure and fixed permeate flux: application to a membrane bioreactor used for wastewater treatment, J. Membrane Sci., 152, 203-210, 1999.

Elimelech, M. and $\mathrm{Ng}, \mathrm{H}$.: Influence of colloidal fouling on rejection of trace organic contaminants by reverse osmosis, J. Membrane Sci., 244, 215-226, 2004.

Freger, V.: Nanoscale heterogeneity of polyamide membranes formed by interfacial polymerization, Langmuir, 19, 4791-4797, 2003.

Hajibabania, S., Verliefde, A., McDonald, J. A., Khan, S. J., and Le-Clech, P.: Fate of trace organic compounds during treatment by nanofiltration, J. Membrane Sci., 373, 130-139, doi:10.1016/j.memsci.2011.02.040, 2011.

Hoek, E. M. V. and Elimelech, M.: Cake-enhanced concentration polarization: a new fouling mechanism for salt-rejecting membranes, Environ. Sci. Technol., 37, 5581-5588, 2003.

Kimura, K., Amy, G., Drewes, J., and Watanabe, Y.: Adsorption of hydrophobic compounds onto NF/RO membranes: an artifact leading to overestimation of rejection, J. Membrane Sci., 221, 89-101, 2003a.

Kimura, K., Amy, G., Drewes, J., Heberer, T., Kim, T., and Watanabe, Y.: Rejection of organic micropollutants (disinfection byproducts, endocrine disrupting compounds, and pharmaceutically active compounds) by NF/RO membranes, J. Membrane Sci., 227, 113-121, 2003b.

Kiso, Y., Sugiura, Y., Kitao, T., and Nishimura, K.: Effects of hydrophobicity and molecular size on rejection of aromatic pesticides with nanofiltration membranes, J. Membrane Sci., 192, 1-10, 2001.

Le-Minh, N., Khan, S., Drewes, J., and Stuetz, R.: Fate of antibiotics during municipal water recycling treatment processes, Water Res., 44, 4295-4323, 2010.

Li, Q. and Elimelech, M.: Organic Fouling and Chemical Cleaning of Nanofiltration Membranes: Measurements and Mechanisms, Environ. Sci. Technol., 38, 4683-4693, 2004.

Nghiem, L. and Coleman, P.: NF/RO filtration of the hydrophobic ionogenic compound triclosan: Transport mechanisms and the influence of membrane fouling, Sep. Purif. Technol., 62, 709$716,2008$.
Nghiem, L. D. and Schäfer, A. I.: Critical risk points of nanofiltration and reverse osmosis processes in water recycling applications, Desalination, 187, 303-312, 2006.

Nghiem, L. D., Vogel, D., and Khan, S.: Characterising humic acid fouling of nanofiltration membranes using bisphenol A as a molecular indicator, Water Res., 42, 4049-4058, 2008.

Nghiem, L. D. and Hawkes, S.: Effects of membrane fouling on the nanofiltration of trace organic contaminants, Desalination, 236, 273-281, 2009.

Ongerth, J. and Khan, S.: Drug Residuals: How Zenobiotics Can Affect Water Supply Sources, J. Am. Water Works Ass., 96, 94101, 2004.

Radjenovic, J., Petrovic, M., Ventura, F., and Barceló, D.: Rejection of pharmaceuticals in nanofiltration and reverse osmosis membrane drinking water treatment, Water Res., 42, 3601-3610, 2008.

Schäfer, A. I., Fane, A. G., and Waite, T. D.: Nanofiltration: principles and applications, New York, Elsevier Advanced Technology, 2003.

Van der Bruggen, B. and Vandecasteele, C.: Removal of pollutants from surface water and groundwater by nanofiltration: overview of possible applications in the drinking water industry, Environ. Pollut., 122, 435-445, 2003.

Van der Bruggen, B., Mänttäri, M., and Nyström, M.: Drawbacks of applying nanofiltration and how to avoid them: A review, Sep. Purif. Technol., 63, 251-263, 2008.

Vanderford, B. and Snyder, S.: Analysis of pharmaceuticals in water by isotope dilution liquid chromatography/tandem mass spectrometry, Environ. Sci. Technol., 40, 7312-7320, 2006.

Verliefde, A. R. D., Cornelissen, E. R., Heijman, S. G. J., Petrinic, I., Luxbacher, T., Amy, G. L., Van der Bruggen, B., and van Dijk, J. C.: Influence of membrane fouling by (pretreated) surface water on rejection of pharmaceutically active compounds (PhACs) by nanofiltration membranes, J. Membrane Sci., 330, 90-103, 2009.

Watkinson, A. J., Murby, E. J., Kolpin, D. W., and Costanzo, S. D.: The occurrence of antibiotics in an urban watershed: From wastewater to drinking water, Sci. Total Environ., 407, 27112723, 2009.

Wells, M.: Log D OW: Key to Understanding and Regulating Wastewater-Derived Contaminants, Environ. Chem., 3, 439-449, 2006.

Xu, P., Drewes, J. E., Kim, T. U., Bellona, C., and Amy, G.: Effect of membrane fouling on transport of organic contaminants in NF/RO membrane applications, J. Membrane Sci., 279, 165175, 2006.

Yangali-Quintanilla, V., Sadmani, A., McConville, M., Kennedy, M., and Amy, G.: Rejection of pharmaceutically active compounds and endocrine disrupting compounds by clean and fouled nanofiltration membranes, Water Res., 43, 2349-2362, 2009.

Zazouli, M. A., Susanto, H., Nasseri, S., and Ulbricht, M.: Influences of solution chemistry and polymeric natural organic matter on the removal of aquatic pharmaceutical residuals by nanofiltration, Water Res., 43, 3270-3280, 2009. 